\title{
ANÁLISE DO IMPACTO REGULATÓRIO NA SAÚDE SUPLEMENTAR
}

\author{
Rafael Soares de Cerqueira ${ }^{1}$ \\ Henrique Ribeiro Cardoso ${ }^{2}$
}

\section{RESUMO}

A atuação regulatória estatal brasileira compreende as mais diversas atividades econômicas de interesse do Estado, dentre elas o serviço de saúde. É feito o estudo da análise de impacto regulatório (AIR) e como ela pode ser aplicada a regulação da saúde suplementar. Utilizada a metodologia de cunho exploratório, por meio da revisão bibliográfica da doutrina ligada ao tema. Contatou-se que a AIR não deve ser utilizada como ferramenta de substituição do processo decisório a respeito da regulação. Demonstrou-se que a regulação deve ser baseada na qualidade, visando otimizar a eficiência no agir da Administração, evitando custos desnecessários para a sociedade.

Palavras-chave: Estado. Políticas regulatórias. Qualidade. Eficiência. Análise do Impacto Regulatório (AIR).

\section{ANALYSIS OF THE REGULATORY IMPACT ON SUPPLEMENTARY HEALTH}

\begin{abstract}
The Brazilian state regulatory agency comprises the most diverse economic activities of interest to the State, among them the health service. A study of the regulatory impact analysis (RIA) and how it can be applied to the regulation of supplementary health. The exploratory methodology was used, through the bibliographic review of the doctrine related to the theme. It was contacted that AIR should not be used as a substitute for the decision-making process regarding regulation. It was demonstrated that regulation should be based on quality, aiming at optimizing efficiency in the management's action, avoiding unnecessary costs for society.
\end{abstract}

Keywords: State. Regulatory policies. Quality. Efficiency. Regulatory Impact Analysis (AIR).

\footnotetext{
${ }^{1}$ Aluno do Mestrado em Constitucionalização do Direito pela Universidade Federal de Sergipe (UFS). Pósgraduado Latu Sensu em Direito Público pelo Centro Universitário Newton Paiva, em convênio com a Associação Nacional dos Magistrados Estaduais - ANAMAGES. Graduado em Direito pela Universidade Federal de Juiz de Fora. Professor de Direito de Direito Administrativo e Direito Ambiental da Graduação da Universidade Tiradentes (UNIT). Autor do livro Direito Ambiental - Série Bibliográfica (publicado pelo Grupo Tiradentes).

${ }^{2}$ Doutor em Direito, Estado e Cidadania, pela Universidade Gama Filho (UGF), com Pós-doutorado em Democracia e Direitos Humanos (IGC/CDH) da Faculdade de Direito da Universidade de Coimbra, sendo ainda pesquisador em estágio pós-doutoral junto ao Programa de Pós-graduação em Ciências Jurídicas da Universidade Federal da Paraíba (PPGCJ/UFPB), na área de concentração Direitos Humanos e Desenvolvimento. É Mestre em Direito, Estado e Cidadania, pela Universidade Gama Filho (UGF), sendo ainda Especialista em Direito Constitucional Processual pela Universidade Federal de Sergipe (FAPESE/UFS). Professor do Programa de Pósgraduação stricto sensu (Mestrado em Constitucionalização dos Direitos/PRODIR) e da graduação da Universidade Federal de Sergipe (UFS). Professor do Programa de Pós-graduação stricto sensu (Mestrado em Direitos Humanos/PPGD) e da graduação da Universidade Tiradentes - UNIT/SE. Membro da Academia Sergipana de Letras Jurídicas (ASLJ). Promotor de Justiça em Sergipe desde agosto de 1997, titular da Primeira Curadoria da Fazenda Pública de Aracaju/SE.
} 


\section{INTRODUÇÃO}

A ação regulatória realizada pelos órgãos governamentais responsáveis pela atuação em determinada área econômica é necessária e imprescindível para a correta harmonização dos mercados envolvidos.

Com o aumento da complexidade das relações sociais, provocado principalmente pelos avanços tecnológicos, o Estado tem sido forçado, continuamente, a buscar cada vez mais resultados mais eficientes, principalmente quando exerce sua função de regulação. Como consequência destas novas relações sociais, houve aumento significativo das normas de regulação e, também, da preocupação existente quanto aos impactos causados por estes instrumentos regulatórios. Isso porque, quando mal utilizados, acabam contribuindo para aumentos de preços ou gerando resultados inesperados, não somente para os consumidores e empresas envolvidas diretamente neste processo, mas também para à sociedade como um todo.

Neste contexto se destaca a atuação das agências reguladoras, que foram inseridas em nosso ordenamento jurídico com a função de implementar a chamada reforma do Estado. Importante lembrar que tais agências tem de respeitar certos limites em sua atuação normativa de regulação.

A análise de impacto regulatório (AIR), como definida pela OECD (2008, p. 14), é a ferramenta política sistemática utilizada para examinar e medir os benefícios, os custos e os efeitos prováveis de uma regulação nova ou já existente.

Desta forma, a AIR revela-se como verdadeiro instrumento de aperfeiçoamento da eficácia e da eficiência da atividade regulatória. De se destacar que isso faz parte de um processo mais amplo, que tem por principal escopo fortalecer a governança regulatória, com a criação de um instrumento baseado na racionalidade, que forneça dados de forma organizada e sistemática, servindo de subsídio para os processos decisórios dos órgãos responsáveis por determinado processo de regulação.

É justamente neste contexto que surge o problema ser estudado no presente artigo: como utilizar a AIR como ferramenta útil para a escolha das medidas que melhor atendem a esses objetivos, da maneira mais eficiente possível e, ainda, com o menor impacto sobre os agentes regulados. 
A regulação, assim como a prestação dos serviços de saúde suplementar, envolve custos. Para que seja possível identificar quais os principais custos de transação envolvidos na questão da saúde, torna-se necessária a participação de todos os agentes envolvidos na questão, quais sejam: a sociedade (em especial os usuários dos planos suplementares), o Poder Legislativo e as Agências Reguladoras. Somente desta forma será possível aperfeiçoar alguns pontos críticos do sistema, diminuindo eventuais inseguranças jurídicas entre os envolvidos no processo e, ainda, diminuindo as dificuldades de acesso aos serviços pela maioria esmagadora da população.

Atenta a estas questões, a Agência Nacional de Saúde Suplementar (ANS) começou a elaborar, no ano de 2017, um normativo para disciplinar a Análise de Impacto Regulatório. No referido documento se encontram diversos pontos importantes, como a identificação de custos envolvidos, o monitoramento e pós-implementação, a formulação de opções regulatórias e análise de cenários e comparações de opções regulatórias.

Portanto, resta cristalino que é necessária uma atuação coordenada do Estado para aplicar de forma eficiente a AIR como um dos instrumentos de análise de eventuais impactos advindos de reformas ou mesmo de criação de novas normas regulatórias, buscando o alinhamento e harmonização desta regulação com as demais políticas públicas.

\section{ANÁLISE DO IMPACTO REGULATÓRIO (AIR)}

O ideal de regulação no Brasil surgiu, ainda que sem os contornos atuais, em 1906, com a assinatura do Convênio de Taubaté, que tinha por escopo conter os altos estoques do café, que refletiam na queda dos lucros e redução nos preços, com a participação do Estado comprando todos os excedentes da produção.

Todavia, somente na década de 90 o Brasil experimentou um fenômeno crescente de criação e expansão de suas agências reguladoras, baseado inicialmente na chamada Reforma Estatal, que culminou, dentre outros pontos, com o processo de desestatização e liberalização de mercados, promovendo uma mudança profunda no atuar estatal, saindo do antigo Estado provedor, para o novo Estado regulador de serviços públicos.

Este novo modelo foi implantado inicialmente no setor de infraestrutura (produção de energia elétrica, exploração de petróleo e gás natural, dentre outros) e tinha como objetivo 
primordial tentar corrigir as falhas de mercado já existentes em determinados setores econômicos, que terminavam por permitir o surgimento de monopólios e problemas na prestação de tais serviços.

Com essa regulação inicial, as agências conseguiram não somente diminuir os valores das tarifas cobradas pelos serviços, mas também criar estabilidade para que as empresas concessionárias pudessem atuar em seus respectivos mercados, reduzindo os riscos de operação e facilitando a captação de novos investimentos. Somente após essa experiência inicial é que tal modelo foi estendido para os demais setores econômicos passiveis de regulação estatal.

Com base nestas experiências iniciais, foram criados diversos princípios que passaram a servir de base para melhorar o funcionamento e a eficiência destas agências, garantindo independência na atuação das mesmas e minimizando eventuais interferências externas. Assim, foi concedida às mesmas independência gerencial, financeira e administrativa. Aos seus dirigentes foi concedida estabilidade e mandado fixo. Passou a ser exigida de seus agentes a respectiva qualificação e especialização técnica, com suas funções sendo exercidas sem a clássica subordinação hierárquica.

Por políticas regulatórias, lato sensu, deve se considerar que são verdadeiras opções exercidas pelos entes incumbidos de tal tarefa, no caso a ANS, no que se refere a escolha de qual dos instrumentos de regulação a seu dispor que devem ser utilizados, com o intuito de implementar os comandos gerais presentes nas políticas públicas de saúde já estabelecidas para o setor regulado.

A regulação pode ser feita diretamente sobre os serviços públicos, para assegurar a sua universalização, qualidade e preço justo ou, ainda, conforme preleciona Aragão (2002, p. 24-25), esta atividade estatal pode ser realizada para "promover a regulação para a competição, como forma de assegurar a livre concorrência no setor privado e, no caso de atividades econômicas sensíveis ao interesse público, o seu direcionamento na senda deste".

Portanto, quando exercem qualquer uma destas formas de regulação, na realidade as agências estão exercendo funções típicas dos três Poderes, a saber: concessão e fiscalização de atividades (Poder Executivo); elaboração de normas e procedimentos (Poder Legislativo) e julgamento e imposição de penalidades as operadoras que se negarem a respeitar os limites impostos (Poder Judiciário). 
E, justamente pela amplitude e impacto que pode ser causado por tal atividade, que se deve ter um cuidado ainda maior no atuar de tais agências, conforme se depreende dos ensinamentos de Cardoso (2017, p. 10) ao afirmar que "o tema se problematiza na medida em que se buscam parâmetros para a edição das normas das agências, identificando seu poder normativo e enquadrando-o nos limites da Constituição Federal, em seu texto vigente".

Somente dentro desta linha de raciocínio é que se torna possível regular o referido mercado, otimizando os objetivos das agências regulatórias, sempre com o menor custo social possível, tendo em vista que qualquer custo proveniente de uma nova regra é sempre absorvido pelos regulados e não pelos reguladores.

Preliminarmente, de forma a possibilitar a utilização da AIR da maneira mais eficaz possível, algumas questões preliminares importantes tem de ser levadas em consideração. Assim, por exemplo, o Estado tem de delinear da maneira mais precisa possível a questão a ser regulada, se preocupando, ainda, se é realmente necessária esta ação do mesmo no caso concreto, em especial pelos possíveis custos e benefícios que surgem com a aplicação das normas de regulação. Diversos questionamentos tem de ser feitos ainda nesta fase rudimentar da elaboração de tais normativos de regulação. Existe base legal para a regulação estatal no caso concreto? Os benefícios da regulação justificam os seus custos?

Ainda dentro desta linha de raciocínio de se destacar os ensinamentos de Aragão (2010, p. 10) quando questiona em relação a regulação se a mesma “(...) é clara, consistente, compreensível e acessível aos administrados e se todas as partes interessadas tiveram a oportunidade de apresentar as suas opiniões e críticas a respeito das normas regulatórias (...)”.

$\mathrm{Da}$ análise de tais questionamentos percebe-se que, na realidade, todos eles estão relacionados a busca da qualidade da regulação que será realizada pelo Estado, alinhadas com as ideias de governança corporativa que, nas palavras de Gonçalves (2006, p. 1): “é a maneira pela qual o poder é exercido na administração dos recursos sociais e econômicos de um país visando o desenvolvimento", ou seja, é a própria capacidade do Estado de planejar, formular e implementar políticas.

Em relação à abrangência do estudo dos impactos advindos de determinada regulação, não se limitando somente a questão da análise da relação custo-benefício, de se considerar as palavras de Aragão (2010, p. 10), ao afirmar que “(...) deve abranger a análise das suas consequências à competitividade nacional, aos grupos socialmente vulneráveis ou excluídos, ao meio ambiente, aos direitos dos cidadãos e empresas". 
Neste sentido, de busca de métodos comuns para a aplicação da AIR, importante destacar a participação da Organização para a Cooperação e Desenvolvimento Econômico (OCDE), sigla em inglês. Esta entidade teve como precursora a Organização para a Cooperação Econômica (OECE), criada no período pós segunda guerra mundial, tendo por escopo ajudar a gerir o Plano Marshall para a reconstrução da Europa.

Atualmente a sua filiação foi estendida a estados não-europeus, sendo composta por mais de trinta países que aceitam os princípios da democracia representativa e da economia de livre mercado, de forma a compartilhar uma plataforma para comparar políticas econômicas, buscando a solução de problemas comuns e coordenando as políticas domésticas e internacionais. Somente em 30 de maio de 2017 o Governo do Brasil formalizou seu pedido de entrada na referida organização.

Nas questões atinentes ao tema da AIR, a OCDE entende que cada país têm de respeitar os princípios de um governo aberto, incluindo transparência e participação no processo regulatório para garantir que a regulação sirva ao interesse público e para que seja informado das necessidades legítimas dos interessados e das partes afetadas pela regulação, além de assegurar que regulações sejam compreensíveis e claras e que as partes possam facilmente compreender seus direitos e obrigações.

É nesta linha de raciocínio que a OCDE define análise de impacto regulatório (AIR) como a ferramenta política sistemática utilizada para examinar e medir os benefícios, os custos e os efeitos prováveis de uma regulação nova ou já existente, fornecendo aos tomadores de decisão dados empíricos e uma estrutura abrangente na qual eles podem avaliar suas opções e as consequências que suas decisões podem ter, servindo, portanto, para garantir que a ação governamental seja justificada e apropriada. Assim o chamado cenário ideal é justamente a criação e adoção de práticas avaliativas do impacto regulatório ex ante, ou seja, ainda antes da implementação prática de tais regramentos, devendo constar, em tais documentos, análises da relação custo-benefício presente no caso concreto, já considerando os impactos sociais da regulação, sob diversos prismas (econômicos, sociais e ambientais).

No caso específico da saúde suplementar, além das diretrizes genéricas anteriormente analisadas, também devem ser criados mecanismos específicos de supervisão ativa dos procedimentos da política regulatória, de maneira a verificar se os objetivos de tal regulação são aptos a promover a qualidade regulatória. 
Com a identificação clara de quais são estes objetivos, torna-se possível avaliar a necessidade ou não de regulação e, anda, como ela pode ser mais efetiva e eficiente na consecução desses objetivos.

Resta patente, portanto, uma das principais preocupações de tal organização, qual seja, a busca constante da qualidade na atividade regulatória utilizando, para tanto, a avaliação do impacto regulatório (AIR) desde os estágios iniciais da elaboração de políticas públicas de saúde.

Quando da aplicação da AIR em certo caso regulatório, podem ser utilizadas diversos métodos, em conjunto ou isoladamente, para que seja possível chegar a um resultado mais satisfatório tanto para as Agências, quando para os operadores dos planos de saúde, o que se faz, normalmente, pela aplicação de metodologias de caráter quantitativo, de percepção mais fácil e cristalinas para os tomadores de decisão, tais como a análise custo-benefício (ACB), a análise custo-efetividade (ACE) e a análise parcial (AP).

Justamente com base nestes apontamentos da feitos pela OCDE, em 2007 foi instituído, pelo Governo Federal, o programa de fortalecimento da capacidade institucional para gestão em regulação (PRO-REG), por meio do Decreto n. ${ }^{\circ}$ 6.062/07, que tinha como objetivo fundamental a melhoria do sistema regulatório. Posteriormente, foi promulgado o Decreto $n^{\circ} 7.963 / 2013$, que institui o plano nacional de consumo e cidadania e cria a câmara nacional das relações de consumo; e, por fim, do Decreto $n^{\circ} 8.243 / 2014$, que institui a política nacional de participação social (PNPS) e o sistema nacional de participação social (SNPS).

O primeiro institui o programa de fortalecimento da capacidade institucional para gestão em regulação (PRO-REG), com a finalidade de contribuir para melhorar o sistema regulatório. Prevê, por exemplo, a criação de mecanismos de prestação de contas e de participação e monitoramento por parte da sociedade civil e da qualidade da regulação de mercados.

Já o segundo institui o Plano Nacional de Consumo e Cidadania e cria a Câmara Nacional das Relações de Consumo. Pela análise detida de seus artigos $4^{\circ}$ e $6^{\circ}$ fica nítida a criação dos chamados eixos de atuação do Plano Nacional de Consumo e Cidadania e, ainda, especificamente em relação a um destes eixos, o chamado de eixo de regulação e fiscalização, encontra-se prevista a necessidade de adoção de políticas e ações que possibilitem a instituição de avaliação de impacto regulatório sob a perspectiva dos direitos do consumidor. 
Por fim, o terceiro decreto institui a Política Nacional de Participação Social - PNPS e o Sistema Nacional de Participação Social - SNPS. Dentre suas principais disposições se encontram o reconhecimento da participação social como direito do cidadão e expressão de sua autonomia, bem como o direito à informação, à transparência e ao controle social nas ações públicas, com uso de linguagem simples e objetiva, consideradas as características e o idioma da população a que se dirige.

Tais normas foram destacadas para relembrar da necessidade de renovação dos ciclos regulatórios, tentando evitar que determinada regulação se transforme, com o passar do tempo, em letra morta e ineficaz, o que é chamado por Jacobzone; Santos (2015, p. 236) de “(...) ciclo de vida da regulação”. Tal medida permite que, com o passar do tempo, se torne possível identificar situações nas quais determinada regulação já se tornou obsoleta e, assim, faz-se necessário o "descarte" das normas de regulação criadas incialmente.

Portanto, resta cristalino que a existe em nosso ordenamento todo o arcabouço normativo inicial para a utilização da AIR. Basta, portanto, aos órgãos envolvidos no processo, interesse institucional na utilização da mesma.

No setor da saúde suplementar tal análise é ainda mais importante, por se tratar de uma espécie de serviço concedido, no qual o Estado opta por transferir a execução de tal serviço as concessionárias privadas, tornando necessário o estudo mais aprofundado dos contornos deste poder normativo das agências. Este também é o entendimento de Cardoso (2017, p. 11) ao afirmar que "como bem se percebe pelo rol de matéria sujeitas a normatização das agências, o cotidiano do brasileiro é altamente afetado pela atuação dessas autarquias de regime especial (...)".

Caso não seja feita uma análise efetiva e real deste impacto, irá aumentar cada vez mais o descompasso entre custos da saúde e a capacidade de pagamento dos possíveis usuários dos planos de saúde suplementar, o que prejudica não somente a competitividade do setor mas, também, o mais importante: o acesso da sociedade ao serviço.

Outro fato que também impacta a questão dos serviços de saúde privados é a crescente interferência do Judiciário no tema o que, na grande maioria dos casos, se baseia tão somente na prescrição médica e sem o necessário conhecimento técnico especializado sobre o assunto.

Feitas estas breves explanações acerca do conceito, amplitude e requisitos básicos que tem de ser respeitados para a realização de uma AIR condizente e compatível com as 
necessidades de cada mercado regulado, torna-se possível o estudo de alguns casos práticos de regulação já aplicados ao setor de saúde suplementar.

\section{A SAÚDE SUPLEMENTAR E A ANÁLISE DO IMPACTO REGULATÓRIO (AIR)}

A atuação regulatória estatal brasileira compreende os serviços de energia elétrica, telecomunicações, produção e comercialização de petróleo, recursos hídricos, mercado audiovisual, planos e seguros de saúde suplementar, mercado de fármacos e vigilância sanitária, aviação civil, transportes terrestres ou aquaviários. Dentre eles, a regulação do serviço da saúde é um dos que mais impacta na vida população, especialmente porque sua prestação alterna-se entre a direta e a transferência destas atividades para o setor privado. Com a hipertrofia estatal, a prestação privada da saúde tem sido a regra, o que intensifica a necessidade de regulação através da Agência Nacional de Saúde Suplementar - ANS.

Nesta linha de raciocínio, especificamente no que se refere aos gastos com a saúde, mesmo após décadas de debates, ainda não existe um posicionamento consensual sobre a definição de quais serviços tem que ser prestados diretamente pelo Estado e quais podem ser repassados para o setor privado. Assim, existe a ideia, ainda que não seja totalmente pacifica, de que caberia ao Estado o financiamento dos serviços de saúde, de forma a garantir o seu aspecto quantitativo capaz de atender as demandas da população, regulando ainda os planos de saúde privados e, de maneira residual, criar subsídios com o intuito de garantir o atendimento para a população carente, desprovida de recursos para ter acesso ao sistema de saúde suplementar.

Essa preocupação foi materializada, na Constituição Federal de 1988, com a inserção de uma seção tratando especificamente das questões relacionadas à saúde. Ficou devidamente positivado que a saúde é um direito de todos e dever do Estado, ficando determinado que as ações e serviços públicos de saúde integram uma rede regionalizada e hierarquizada, o Sistema Único de Saúde (SUS), com características de universalidade, integralidade e gratuidade. Por fim, ficou estabelecido que a iniciativa privada poderia atuar em tal atividade, sendo regulada pelo Estado.

O marco inicial da ideia de se regulamentar a saúde suplementar foi iniciado antes mesmo da criação da ANS, aproximadamente a partir de 1992, com a participação, à época, 
de médicos, alguns ministérios (como o da Fazenda, da Saúde e da Justiça) e, obviamente, do legislativo federal. Neste contexto, os assuntos que mereceram mais destaque foram a característica de fins lucrativos das empresas do setor e a necessidade de se buscar ampliar as coberturas já existentes.

Assim, o órgão responsável por iniciar a regulação do setor foi a Superintendência de Seguros Privados (SUSEP), já com diversos objetivos ainda presentes atualmente, como evitar o aumento desregrado dos valores das mensalidades dos planos de saúde suplementar.

Posteriormente, a responsabilidade pela regulação de mercado passou a ficar a cargo da Agência Nacional de Saúde Suplementar (ANS), criada e regulamentada pela Lei Federal $\mathrm{n}^{\mathrm{o}}$ 9.961/2000 que trouxe, em seu bojo, como objetivo ínsito de tal órgão, normatizar e fiscalizar a atuação das operadoras setoriais, através de diversos mecanismos e ações. Com isso passou a promover a integração do SUS à saúde suplementar, controlar e fiscalizar a questão dos reajustes de preços dos planos, definir as características gerais dos instrumentos contratuais dos planos de saúde, promover a criação, atualização e ampliação constante de um rol de coberturas mínimas obrigatórias e a estabelecer quais são os critérios a serem observados, tanto para o credenciamento, quanto para o descredenciamento de prestadores.

Esta regulação no campo da saúde, normalmente consiste em “(...) expedição de autorizações de funcionamento, (...) definição do percentual de reajuste anual aplicado aos planos de contratação individual ou familiar, entre outras determinações", conforme prelecionam BAHIA e VIANA (2002 p. 108).

Neste campo de atuação também se inclui o controle da relação existente entre os prestadores de serviços de saúde com os usuários de planos privados de saúde, tendo em vista a necessidade de se promover e garantir o interesse público envolvido em tal questão e, ainda, desenvolver as ações práticas necessárias para a implementação das políticas de saúde no Brasil.

A questão da definição de quais procedimentos são considerados mínimos e obrigatórios, que têm que ser fornecidos pelas operadoras de saúde, foi devidamente regulamentado, inicialmente, com a edição da Lei Federal $n^{\circ}$ 9.656/1998 que determinou, ainda que de forma genérica, que tais empresas deveriam garantir a cobertura assistencial médico-ambulatorial e hospitalar, compreendendo partos e tratamentos, com padrão de enfermaria, centro de terapia intensiva, ou similar, quando necessária a internação hospitalar, 
das doenças listadas na Classificação Estatística Internacional de Doenças e Problemas Relacionados com a Saúde (CID), da Organização Mundial de Saúde.

Todavia, posteriormente, somente com o início da prestação de tais serviços sob estas novas diretrizes se tornou possível detectar inúmeros problemas comuns. Desta forma, tornou-se necessária a elaboração de alguns normativos específicos, dentre os quais a mais importante, à época, foi a Resolução do Conselho de Saúde Suplementar (CONSU) no 10/98.

Esta norma fixou qual a lista básica de procedimentos de cobertura obrigatória pelos planos de saúde, sendo complementada alguns anos após com a edição das Resoluções da Diretoria Colegiada (RDC's) no 41/2000 e no 67/2001. Posteriormente, no ano de 2004, este rol de procedimentos médicos obrigatórios foi reeditado por meio da Resolução Normativa $(\mathrm{RN}) \mathrm{n}^{\mathrm{o}}$ 82/2004, também devidamente atualizada pelas RNs $\mathrm{n}^{\mathrm{o}} 167 / 2008,262 / 2011$ e $338 / 2013$.

Todos estes normativos tinham um propósito básico e claro, que era o de garantir uma cobertura mínima para os procedimentos considerados indispensáveis ao diagnóstico e tratamento de todas as doenças que compõem a Classificação Internacional de Doenças (CID10), podendo a mesma ser ampliada unilateralmente pelos planos de saúde caso entendam ser viável do ponto de vista econômico.

Esta atualização do rol de procedimentos cobertos é sempre feita por um grupo técnico, composto por representantes de entidades de defesa do consumidor e de operadoras de planos de saúde, por profissionais da área da saúde e por servidores da Agência, sendo posteriormente submetida à avaliação da sociedade por meio de consulta pública, com participação aberta a todos os interessados, ou seja, o que se busca, na realidade, é que esta ampliação do rol não represente uma imposição unilateral por maio da Agência Nacional de Saúde (ANS), mas sim que seja fruto de um debate social amplo, de maneira a que passem a constar em tais documentos os verdadeiros anseios da sociedade em geral.

Esta regulação, apesar de provocar impactos sobre os prestadores de saúde suplementar, veio com o intuito de fazer valer questões envolvendo o direito do consumidor que contrata um determinado plano de saúde, para preencher uma lacuna antiga que carecia de regulação específica.

Do ponto de vista das operadoras de planos de saúde suplementar, as mesmas são forçadas a criar grandes mudanças organizacionais em seu funcionamento, para que seja implantada a profissionalização necessária ao cumprimento destas novas normas ligadas a 
cobertura dos segurados, tendo como consequência a necessidade das mesmas passarem a suportar um grande ônus operacional e financeiro. Neste caso, tal intenção regulatória se justifica pois, somente desta forma, é possível dar mais transparência para o consumidor que passa a saber claramente o que está contratando.

Outro aspecto que certamente impacta tais operadoras é o fato de que as mesmas muitas vezes são "pegas de surpresa". Isso faz com que tenham pouco tempo para que se adaptem as novas realidades e as novas obrigações impostas para se enquadrar e atender ao previsto na legislação. Caso não se preparem e se adequem rapidamente, terão vários pedidos de autorização de procedimentos negados, serão penalizadas pecuniariamente pelo pagamento de multas e sofrerão sanções de cunho administrativo, como proibições em princípio temporárias para se ofertas planos a novos usuários do sistema.

No que tange a tentativa de controle do reajuste dos preços praticados pelas operadoras, a ANS editou a Resolução Normativa (RN) 63/03, que tinha por escopo principal a criação de um programa de incentivo para a adaptação dos contratos antigos, em especial no que se referia aos limites para reajuste no valor da mensalidade e aos prazos relativos ao cumprimento da carência pós migração.

O controle destes reajustes, da forma como foi feito, acabou por provocar defasagens nos valores praticados pelo setor, tendo em vista que, normalmente, os índices utilizados pela ANS são menores do que o IPCA, o que impacta diretamente nos insumos utilizados para a prestação dos serviços médicos e que servem para compor o custo de tais serviços.

Para maximizar e acelerar a questão dos reajustes, a ANS passou a adotar um mecanismo chamado de Termos de Compromisso de Condutas (TCC), que era celebrado entre algumas operadoras e a referida agência. Desta forma, o que se buscou foi fazer com que os alguns contratos celebrados antes de 1999 e anda não devidamente adaptados à Lei 9.656/98, que possuíam em seu bojo cláusulas de reajuste desprovidas de previsão clara de qual índice a ser aplicado, fossem submetidos aos TCCs.

Essas adequações impostas as operadoras promove um maior detalhamento e uma menor flexibilidade das mesmas em relação a prestação de contas e exigências que precisam ser preenchidas, fazendo com que tais empresas não possam mais interpretar a questão da sustentabilidade como um mero desejo, mas sim como uma verdadeira obrigação, imposta por lei. 
Também foi criado o sistema de co-participação nos contratos de planos de saúde com o advento da Resolução CONSU n ${ }^{\circ}$ 8/98, visando principalmente o combate a possíveis abusos e má-utilização dos planos. Tal prática regulatória, quando bem utilizada, funciona como verdadeiro incentivo ao usuário do plano, quando da escolha de quais procedimentos pretende realizar, tendo em vista que, na maioria dos casos, as pessoas não tem a menor ideia de quais são os custos dos procedimentos a que são submetidos, já que o consumidor que não é usuário deste tipo de plano não arca diretamente com tais despesas, não sofrendo um impacto direto em seu orçamento e, assim, não se importando com a quantidade de exames, por vezes desnecessários, que são prescritos pelos médicos. Se usado de forma correta, tal mecanismo não prejudica os consumidores, pois não dificulta o acesso dos mesmos a tais procedimentos.

Também foram implantadas modificações que afetaram um segmento específico das operadoras de planos de saúde suplementar. Este grupo específico de empresas comercializa planos de saúde para pessoa física ou pessoa jurídica nos quais os beneficiários utilizam uma estrutura própria e/ou contratada pela operadora, englobando médicos, hospitais, laboratórios, dentre outras estruturas.

Esta espécie de operadora teve de se adaptar, voltando suas unidades para ter seu foco agora voltado para o mercado em si mesmo. Tiveram de aumentar drástica e rapidamente sua assessoria jurídica, os produtos ofertados e o cadastro de seus usuários. Também tiveram que buscas a ampliação de sua área de vendas, para se tornar mais competitivas. De forma resumida: antes, este tipo de operadora se preocupava quase que exclusivamente no atendimento ao cliente e, com a entrada em vigor das novas normas regulatórias, passou a ter que possuir em seus quadros pessoal qualificado e, por vezes, até mesmo criar um setor específico preocupado em acompanhar exclusivamente as questões regulatórias, analisando em tempo real os novos normativos da ANS. Todos estes fatores também contribuíram para aumentar os custos dos serviços ofertados pelas empresas do setor.

Novas determinações também foram criadas no que se refere às questões tecnológicas, que forçaram as operadoras a promover o aperfeiçoamento de seus sistemas informatizados de gestão, em especial no tocante a criação de novos softwares que tem por objetivo atender ao crescimento do número de clientes decorrentes do somatório de dois tipos de operadoras específicos: as de autogestão e as de medicina de grupo. Isso porque a ANS passou a exigir que todos os processos envolvendo questões com os usuários tivessem que ser 
feitos no formato eletrônico, praticamente abandonado o processo físico anterior. Assim, surgiu a necessidade de criação de novas tecnologias como a biometria, o acesso a informações ao usuário via internet (rede credenciada, etc.).

No campo das externalidades (fora, portanto, do âmbito da regulação), talvez as principais mudanças que já se encontram em andamento sejam as alterações demográficas populacionais. Isso porque o envelhecimento da população e ainda a melhoria nas condições de vida certamente irá aumentar a longevidade de nossa população, o que acarretará custos extras para a saúde suplementar.

Paralelamente, também ocorre uma mudança na frequência, na distribuição e nos fatores determinantes dos problemas de saúde na população brasileira, baseada principalmente numa melhora nas condições de vida, em especial na melhora das condições econômicas e sociais, gerando, desta forma, uma diminuição das doenças infectocontagiosas e uma maior incidência de doenças crônico-degenerativas, também com impactos ainda incertos no sistema de saúde.

Além disso, não se pode deixar de destacar o impacto causado na regulação por outra externalidade: as decisões judiciais.

Inicialmente estas versavam, principalmente, sobre a necessidade de readequação dos planos antigos, anteriores a 1999. Com isso, se buscava a garantia de condições que promovessem a migração e adaptação destes consumidores aos novos contornos regulatórios criados no setor. O problema é que, na grande maioria dos casos, tais determinações judiciais não seguiam os parâmetros contidos nos próprios normativos da ANS, entidade responsável pelo setor, o que gerava não somente insegurança jurídica para as operadoras de saúde, mas também defasagens nos preços praticados.

Ainda dentro desta questão do impacto da atuação do Judiciário, especificamente no que se refere aos reajustes, o mercado da saúde suplementar sofreu fortes impactos, tendo em vista as inúmeras decisões judiciais que obrigavam as seguradoras dos planos suplementares a promover este reajuste dos contrato antigos aplicando percentuais abaixo dos determinados pelas própria agencia reguladora. Isso promoveu o desequilíbrio dos cálculos atuariais referentes aos planos individuais.

E esta judicialização não abrange tão somente as questões citadas anteriormente, mas também as que envolvem o acesso a coberturas não contratadas. Com isso, conforme já 
observado anteriormente sobre a gestão de riscos, ocorre um aumento do chamado risco judicial das operações de planos de saúde.

Todavia, toda estas atividades regulatórias anteriormente citadas, ainda que embebidas no nobre propósito de diminuir eventuais falhas existentes no mercado, certamente trazem consigo um custo. Tal fator é chamado de custo para o cumprimento da regulação e se subdivide em: custo financeiro, custo substancial de cumprimento e custo administrativo.

O primeiro tipo de custo, o financeiro, é produto da transferência direta de valores ao governo ou ao órgão regulador por meio do pagamento de taxas e encargos, tais como aquelas cobradas para registro ou cadastro de novos produtos junto ao regulador.

Já o chamado custo substancial de cumprimento é resultado da necessidade de adaptação da atividade produtiva às normas emanadas pelo regulador, ou seja, os gastos despendidos com a adequação de edificações e instalações físicas aos normativos da Agência Nacional de Vigilância Sanitária (ANVISA) e da Agência Nacional de Saúde (ANS).

Por último, o custo de administração, resultante da constante expansão das atividades administrativas por exigência do órgão regulador ou para adequação às suas normas, tendo como principal exemplo a necessidade de criação de rotinas para a troca de informações com o regulador.

No Brasil, infelizmente, ainda não existem estudos capazes de estimar com precisão os custos totais do cumprimento à atividade regulatória do Estado. No entanto, existem estimativas de que, levando em conta a complexidade de nosso marco regulatório, estes valores podem ultrapassar o percentual de dez por cento de nosso PIB.

Além disso, todas estas medidas práticas citadas a título exemplificativo terminam por provocar, muitas vezes, um efeito não desejado neste mercado: a concentração das empresas prestadoras, fazendo com que muitas operadoras se unam ou, ainda, comprem umas às outras.

Todavia, isso não quer dizer necessariamente que seja um efeito ruim, já que a ideia de concentração não pode ser considerada automaticamente como a criação de um cartel. Isso porque a questão da concentração, grosso modo, significa que existem poucas empresas ofertando seus serviços. Já a cartelização significa que existem várias empresas atuando no mercado, mas existe uma combinação entre as mesmas no que se refere ao preços a serem praticados ou, ainda, à área geográfica na qual pretendem atuar. 
Com isso, talvez o principal impacto apontado pela AIR, a concentração, não seja necessariamente um grande problema, já que a mesma só passa a ser nociva quando inexiste competição entre as operadoras, ainda que se diga que as chamadas barreiras à entrada, tanto de empresas nacionais, quanto internacionais, seja considerada elevada. Com isso, se utilizada de maneira produtiva essa prática serve, na realidade, para que seja possível atingir a denominada economia de escala o que, a priori, aumenta o grau de eficiência na prestação de tais serviços.

Portanto, verifica-se a real importância da implementação prática da AIR como instrumento de análise dos impactos regulatórios diretamente promovidos pela ANS.

\section{CONCLUSÃO}

De acordo com o abordado no presente artigo, fica clara a necessidade de utilização da AIR como instrumento de suporte no processo de tomada de decisões relativas a atividade regulatória. Isso porque tal instrumento permite à ANS ter acesso a uma visão mais sistêmica da questão, promovendo a integração dos diversos objetivos políticos macros com os objetivos específicos do mercado da saúde suplementar.

Esta utilidade se torna evidente tendo em vista que os principais problemas existentes na atividade regulatória são justamente a falta de clareza do que se pretende com a elaboração de determinada norma; a complexidade do mercado a ser regulado; o processo de defasagem sofrido ao longo do tempo por falta de atualização; e uma comunicação insuficiente entre os agentes envolvidos nos dois pólos da questão.

No Brasil, assim como na maior parte dos países em desenvolvimento, as ações voltadas ao aperfeiçoamento da governança regulatória ainda são muito tímidas, mesmo se reconhecendo que esta atuação acanhada das agências já pode ser considerada importante do ponto de vista da diminuição da incerteza regulatória, conforme relatório elaborado pela OCDE.

Quanto a aplicação da AIR na regulação da saúde suplementar, a ANS comprometeu-se publicamente a incluir a mesma em sua Agenda Regulatória a partir de 2013, culminando com alguns pequenos avanços, como a elaboração do Sumário Executivo de Impacto Regulatório, instrumento voltado à identificação dos potenciais efeitos de novas 
opções regulatórias. Mas, infelizmente, a referida agência ainda não foi capaz de avaliar de forma quantitativa os impactos das regulamentações produzidas.

Com isso, pode-se afirmar que a AIR não deve ser utilizada como ferramenta de substituição do processo decisório a respeito da regulação, mas sim como um método complementar, que permita deixar claro, dentre outras coisas, a necessidade de se criar ou de se revisar os normativos regulatórios ligados a saúde suplementar, a criação de programas educativos e informativos para os usuários dos serviços de saúde suplementar e a harmonização entre as políticas públicas em geral e seu detalhamento através das atividades regulatórias.

Assim, o objetivo principal deste estudo é demonstrar que a busca da regulação baseada na qualidade, na realidade é a busca pela eficiência no agir da Administração, evitando custos desnecessários para a sociedade e, ainda, reduzindo sensivelmente a margem de discricionariedade do agente regulador.

\section{REFERENCIAS}

ALMEIDA, Fernando Dias Menezes de. Considerações sobre a "Regulação" no Direito Positivo Brasileiro. Revista de Direito Público da Economia - RDPE. Belo Horizonte: Fórum, ano 3, n. 12, out./dez. 2005.

ALVES, Sandro Leal. Análise Econômica da Regulamentação e do Setor de Planos e Seguros de Saúde no Brasil. 1ed. v. 1. 156p. Rio de Janeiro: FUNENSEG, 2004.

ARAGÃO, Alexandre Santos de. Agências reguladoras e a evolução do direito administrativo econômico. 1. ed. Rio de Janeiro: Forense, 2002.

Análise de Impacto Regulatório - AIR. Revista de Direito Público da Economia (RDPE), ano 8, n. 32, pp. 9-15, out./dez. 2010.

BAHIA, Lígia; VIANA, Ana Luiza. Regulação e Saúde: estrutura, evolução e perspectivas da assistência médica suplementar. Rio de Janeiro: ANS; 2002.

CARDOSO, Henrique Ribeiro. O Poder Normativo das Agências Reguladoras. 2. ed. rev. e atual. Rio de Janeiro: Lumen Juris, 2016. 
CUÉLLAR, Leila. As agências reguladoras e seu poder normativo. São Paulo: Dialética, 2001.

FERRAZ JÚNIOR, Tércio Sampaio. O poder normativo das agências reguladoras à luz do princípio da eficiência. In: ARAGÃO, Alexandre Santos de (coord.). O poder normativo das agências reguladoras. Rio de Janeiro: Forense, 2006, pp. 271/297.

GONÇALVES, Alcindo. O conceito de Governança. Artigo. Doutor em Ciência Política pela USP e professor titular do Programa de Mestrado em Direito da Universidade Católica de Santos. CONPEDI, Manaus, Anais, 2006. Disponível em: $<$ http://www.egov.ufsc.br/portal/sites/default/files/conceito_de_governanca.pdf $>$. Acesso em: 25 de julho de 2017.

JACOBZONE, Stéphane; SANTOS, Luiz Albertoc dos. Capítulo 6: Supervisão regulatória na experiência mundial recente. In: SALGADO, Lucia Helena; FIUZA, Eduardo Pedral Sampaio (orgs.). Marcos regulatórios no Brasil: aperfeiçoando a qualidade regulatória. Rio de Janeiro: IPEA, pp. 223-266, 2015.

MARQUES NETO, Floriano Peixoto de Azevedo. Regulação estatal e interesses públicos. São Paulo: Malheiros, 2002.

Disponível

Agências Reguladoras Independentes: instrumentos do fortalecimento do Estado. 01 de agosto de 2017.

ORGANIZATION FOR ECONOMIC CO-OPERATION AND DEVELOPMENT. Building an institutional framework for regulatory impact analysis. Version 1.1. Regulatory Policy Division Directorate for Public Governance and Territorial Development. Paris, 2008.

VALENTE, Patricia Rodrigues Pessôa. Avaliação de Impacto Regulatório: uma ferramenta à disposição do Estado. Dissertação de Mestrado. 218 páginas. Universidade de São Paulo (USP). Faculdade de Direito. 2010. Disponível em: <http://www.teses.usp.br/teses/disponiveis/2/2134/tde-26032012-092844/pt-br.php>. Acesso em 27 de julho de 2017. 